\title{
Book review: "The physical and social environment, quality of school, and subjective health and health behaviours of adolescents" by Joanna Mazur and Agnieszka Małkowska-Szkutnik (eds.)
}

\author{
Zbigniew Izdebski \\ Department of Biomedical Basic Development and Sexology, Faculty of Pedagogy, University of Warsaw, Poland \\ Department of Humanisation in Medicine and Sexology, Faculty of Medicine and Health Science, University \\ of Zielona Góra, Poland
}

ADDRESS FOR CORRESPONDENCE: Zbigniew Izdebski, Faculty of Medicine and Health Science, University of Zielona Góra, 2 St. Energetyków, 65-729 Zielona Góra, Poland, e-mail: z.izdebski@ips.uz.zgora.pl

Since many years, adolescence is considered a key period for the shaping of health behaviours. These, in turn, had a direct impact on the health condition of adolescents, their later health in adulthood, as well as the health of their future families.

English-language studies on the determinants of health behaviours attach increasing importance to individual and environmental factors as well as the interactions among them. School, aside from family, is the most important element of the growing-up environment, influencing students' well-being and their engagement in health-conducive or health-impairing behaviours. An assumption can be made that some behaviours accumulate in some schools and environments because students influence each other. The correlation between the characteristics of a school and its students can be bidirectional. Schools in which the atmosphere is better, which meet teaching and education standards, and properly perform the custodial function of a school can expect more positive student health behaviours. On the other hand, the presence of students with problematic behaviours may negatively affect a school's climate. One can also expect social problems characteristic of elite schools, in which the phenomenon of rivalry intensifies. Physical conditions are also significant, e.g. the standard of the building, the school's surroundings.

Due to the above, it is worth noting a project funded by Poland's National Science Centre, conducted in 20142017 at the Institute of Mother and Child in cooperation with the Faculty of Education of the University of
Warsaw. At the assessment stage, the project ranked top on the list of the OPUS5 competition (no. 2013/09/B/ HS6/03438). The full title of the project was „The physical and social environment, quality of school, and subjective health and health behaviours of adolescents application of structural and path models estimated on data of a hierarchical structure" [1]. The monograph, which is the subject of this review, was published in 2017 and is the outcome of cooperation among seven national research centres. The authors' published report on completed tasks is composed of three substantive parts and a fourth presenting documentation of the project. The report was illustrated with examples of posters presented at academic conferences.

The project's distinguishing feature was the use of data of a hierarchical structure, which is still rarely encountered in Polish studies, in particular on this scale. An online survey was conducted among 4085 students from 70 junior secondary schools located across Poland [2]. The schools were randomly selected among those that had had a comprehensive external evaluation conducted in the previous year as part of the national system for evaluating educational facilities. As a result, data were obtained from two independent sources. Indicators of how the students' health and lifestyle had changed was checked against findings of the staff of the regional education authorities performing the school evaluations. An additional source of data was a survey relating to the schools' physical and psychosocial environment, completed by the headmasters of junior high schools. 
It should be pointed out that the above method of school selection required high organisational efficiency and travelling to small towns located across the country, without the possibility of inviting replacement schools to the survey. The inclusion criterion was access to the results of the current evaluation in the SEO database, which significantly narrowed the sampling frame.

An additional advantage of the project was a careful selection of research tools. The researchers had been active in the Health Behaviour in School-aged Children (HBSC) network for years [3]. As a result, a number of the questions and measurement scales used were sourced from the protocols of subsequent rounds of the HBSC surveys completed by students (individual level) and headmasters (school level). In addition, experiences from other projects were sought, including the scales and questions adapted previously into Polish (Strength and Difficulties Questionnaire - SDQ, Child Health and Illness Profile - Adolescent Edition - CHIP-AE). Thus, they were tested tools, used in Poland multiple times. The layout of the "School and Health" questionnaire was included, along with the documentation, in the report.

The first part of the monograph includes the theoretical foundations of the study. Attention was drawn to the interdisciplinary nature of the conceptualisation of the influence of the school on students' health. A theoretical model was developed on the basis of research hypotheses. Correlations among hypotheses relating to the influence of the school environment on health and health behaviours were described in reference to the model proposed by Bonell et al. [4]. The following findings were analysed: the direct correlation between the school environment and student health behaviours, also in the context of peer relations and the students' cognitive functioning; the mediating role of the school environment in the social socioeconomic status of the family, the environment, and health; and the impact of the school's external factors on students health and health behaviours. The multi-level understanding of the correlations between the school and health, proposed by the authors, provides an opportunity for a deeper analysis of the acquired data.

The second part of the project involved methodological objectives. Ten research questions were defined at the stage of designing actions, creating a research pattern using the hierarchical structure of data. Individual research data were precisely located in that pattern. Variables and indicators in the analyses were separated into those relating to the school and non-school environment. In the first case, the following levels were marked out: the school level (external data from the SEO system and from the survey completed by the headmaster), the class level (students' aggregated data), and the student level (perception of the school environment). Nonschool factors were analysed only based on the surveys completed by students. The innovation consisted here in dividing them into distant factors (e.g. material conditions), indirect factors (e.g. social support), and close factors (e.g. life skills).

In presenting the results in the third part of the report, coherence was preserved with the previously defined research questions. The methodological aspects of the analyses were also emphasised, indicating publications in which, in accordance with the project title, structural models and data of a hierarchical structure were used. Attention was also drawn to the strands of analyses that went beyond the initial objectives. At the project implementation stage, the example of students with chronic diseases was subjected to detailed analysis. Drawing attention to the population of students with long-term health conditions seems important due to their special educational and developmental needs. It was demonstrated that the students with chronic diseases, in comparison with healthy students, had a less positive view of the school environment. Taking into account the broad diversity of needs among students with chronic diseases, the research results may contribute to a better understanding of this student group.

The output of the project, described in the reviewed publication, is a draft report available from the website of the Institute of Mother and Child [5], 15 articles, three chapters in monographs, 18 conference presentations, and a doctoral dissertation (approved in February 2019). The research team continued, after 2017, to use the collected material in subsequent publications. The authors enclosed summaries of these publications, giving the reader a better picture of the scope of the covered topics. Considering the potential of the conference presentations, one postulate for grant recipients would be to prepare a full-text version of those preliminary analyses.

It is worth emphasising that this research project, along with a number of publications written as a result of its completion, can be included in the strand of research on social inequalities in health. Attention was drawn to the extent to which a well-functioning school can contribute to levelling such socially determined inequalities. In the SEO evaluation system, throughout the duration of the project, there were 12 evaluation requirements providing a basis for school assessment. At least one of them pertained to the social situation of the students (W6 - the school and the facility supports student development, taking into account their individual situation). It appears from the sets of tables included in the report that indicators of students' quality of life significantly increased in the schools that obtained a positive assessment in that area (Table 8, p. 114, and Table 8, p. 115). An interesting result is the improved perception of support from other students in the class and from teachers in the schools that scored higher in all 12 assessment areas (Table 15, p. 117, and Table 16, p. 118). This kind of result needs to be more widely publicised, and the 
study itself would be worth repeating in the new educational system, i.e. following the abolition of junior secondary schools, in various age groups and school types. It would be worthwhile to take examples from other countries (Germany [6], Canada [7], Wales [8]), to develop research on the influence of the school environment on student health, using data of a hierarchical structure and available data sources, such as the HBSC surveys.

According to Prof. Bogusław Śliwerski [9], the research results presented in the report provide a kind of "photograph of the state of consciousness and feelings of the respondents" regarding issues related to health and school. Drawing attention to the limitations of the studies (such as their quantitative nature and the use of criteria of the external assessment, criticised by selected circles), Prof. Śliwerski underlined the most significant results and pointed out that they are coherent with the areas to which he had been drawing attention for years while analysing the Polish education system and the functioning of students in schools. He refers to the need to increase the level of school autonomy, which may become a factor greatly influencing a more positive assessment of schools by students, and which can also correlate with an improvement in student health.

The results obtained from the studies and presented in the report titled „The physical and social environment and the functioning quality of the school and the subjective health and health behaviours of adolescents" provide a valuable source of data on adolescents, their health, and the school environment. They can be a starting point for people planning qualitative studies of this issue and for people designing intervention measures in schools.

\section{DISCLOSURE}

The author reports no conflict of interest.

\section{References}

1. Mazur J, Małkowska-Szkutnik A (eds.). Środowisko fizyczne i społeczne oraz jakość funkcjonowania szkoły a zdrowie subiektywne i zachowania zdrowotne nastolatków [The physical and social environment, quality of the school and the subjective health and health behaviours of adolescents]. Institute of Mother and Child, Warsaw 2017. Available from: https://kalimu.github. io/downloads/instytut_net.pdf (accessed: 2 October 2019).

2. SEO - System Ewaluacji Oświaty [System of education evaluation]. Available from: http://www.npseo.pl (accessed: 2 October 2019).

3. Poland has been taking part in the HBSC surveys since 1989 Available from: http://www.hbsc.org (accessed: 2 October 2019).

4. Bonell CP, Fletcher A, Jamel F, et al. Theories of how the school environment impacts on student health: systematic review and synthesis. Health Place 2013; 24: 242-249.
5. Mazur J, Dzielska A, Woynarowska B, Zawadzka D. Środowisko gimnazjów w opinii uczniów i dyrektorów szkół [Junior high school environment in the opinion of students and school headmasters]. Institute of Mother and Child, Warsaw 2015. Available from: http://www.imid.med.pl/images/IMiD_ srodowisko-gimnazjalistow.pdf (accessed: 2 October 2019).

6. Czerwinski F, Finne E, Kolip P, Bucksch J; HBSC Study Group Germany. Individual and school level correlates of moderate to vigorous physical activity among school-children in Germany-a multi-level analysis. BMC Public Health 2015; 15: 393.

7. Saab H, Klinger D. School differences in adolescent health and wellbeing: findings from the Canadian Health Behaviour in School-aged Children Study. Soc Sci Med 2010; 70 (6): 850-858.

8. Moore GF, Littlecott HJ, Evans R, et al. School composition, school culture and socioeconomic inequalities in young people's health: Multi-level analysis of the Health Behaviour in School-aged Children (HBSC) survey in Wales. Br Educ Res J 2017; 43 (2): 310-329.

9. Śliwerski B. Jakość szkoły a zdrowie uczniów [Quality of school and students health]. Available from: http://sliwerski-pedagog. blogspot.com (accessed: 2 October 2019). 